Gut, 1972, 13, 874-879

\title{
The effect of vagotomy on gastric adaptation
}

\author{
D. C. CARTER ${ }^{1}$, H. N. WHITFIELD ${ }^{2}$, AND I. B. MACLEOD \\ From the Department of Clinical Surgery, University of Edinburgh
}

SUMMARY Gastric adaptation was impaired immediately after the performance of complete vagotomy in a series of 20 acute experiments in the dog. Preliminary isolation of the intact vagi in 10 of these animals produced alterations in adaptation similar to those seen after vagal division.

It is concluded that alterations in gastric adaptation are not a reliable intraoperative aid to complete vagotomy. These findings may be significant in the interpretation of all intraoperative tests for vagotomy.

The ultimate success of vagotomy and drainage in the surgical treatment of duodenal ulcer depends to a large extent on complete section of the gastric vagi. The knowledge that complete vagotomy is difficult to achieve has encouraged the development of techniques capable of detecting intact vagal fibres at the time of initial operation.

The most widely known intraoperative aid to complete vagotomy is perhaps the electrical stimulation test described by Burge and Vane (1958). The selective nerve stain, leucomethylene blue, described by Lee (1969), and the method described by Grassi (1971), offer alternative approaches to Burge's method, but none has achieved wide uncritical acceptance.

The intact innervated stomach accepts an increasing volume of content with only a minimal rise in intragastric pressure (Cannon and Lieb, 1911; Aune, 1969; Stadaas and Aune, 1970). The loss of this phenomenon of gastric adaptation after vagotomy has been suggested as the basis of an intraoperative test for complete vagotomy (Koster and Madsen, 1970). In view of the controversy surrounding all intraoperative techniques, the present study was designed to assess this method in a controlled experimental situation.

\section{Materials and Methods}

Twenty adult mongrel dogs were fasted overnight. In 16 dogs anaesthesia was induced by intravenous nembutal $(24 \mathrm{mg} / \mathrm{kg})$ and the animals were allowed

'Present address: Department of Surgery, Makerere University, Kampala, Uganda.

${ }^{2}$ Present address: Military Hospital, Tidworth, Hants.

Received for publication 5 September 1972. to breathe spontaneously after endotracheal intubation. In four dogs (nos. 8, 9, 19, 20) anaesthesia was induced by intravenous thiopentone $(20 \mathrm{mg} / \mathrm{kg}$ ) and maintained by a mixture of oxygen $(21 / \mathrm{min})$, nitrous oxide $(1.5 \mathrm{l} / \mathrm{min})$, and halothane $(0.5-2 \%)$ administered through an open circuit.

The abdomen was entered through an upper midline incision and a $1000 \mathrm{ml}$ balloon (condom) of known pressure-volume response placed in the stomach via a small duodenal incision. The balloon was connected by a three-way tap to a reservoir of $0.9 \%$ saline and via a Sanborn $267 \mathrm{BC}$ transducer and Sanborn 3500 pre-amplifier to a pressure recorder (Fig. 1).

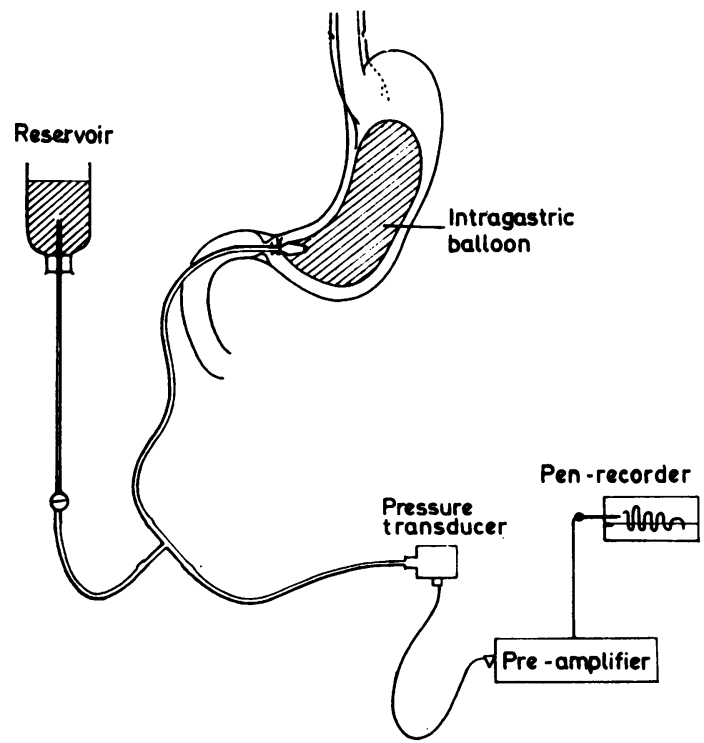

Fig. 1 Diagram of apparatus. 
SERIES A

In 10 animals (series $A$ ) the experiment proceeded as follows:

\section{Basal state}

The intragastric balloon was filled in a stepwise manner with $100 \mathrm{ml}$ increments of saline to a total of $600 \mathrm{ml}$. The basal intragastric pressure was recorded after each increment once the pressure had stabilized. The pressure engendered by $600 \mathrm{ml}$ of saline is henceforth referred to as the end-filling pressure. The balloon was then emptied gravitationally with pressure measurement after evacuation of each 100 $\mathrm{ml}$ of content.

\section{Incomplete vagotomy}

The anterior vagal fibres were then divided subdiaphragmatically at the oesophageal hiatus and the sequence of filling and emptying was repeated as in the basal state. In four of the $\mathbf{1 0}$ animals the posterior vagal fibres were divided instead of the anterior fibres at this stage.

\section{Complete vagotomy}

The remaining vagal fibres were then divided and the sequence of pressure readings was repeated. The denuded oesophageal hiatus was again carefully inspected and if further fibres were detected and divided (as in animals 5 and 8) the intragastric pressure responses were measured once more.

\section{Oesophageal transection}

The mobilized abdominal oesophagus was then divided between crushing clamps and the stomach swung forward to confirm the absence of residual vagal strands. A further set of pressure readings in response to filling and emptying was undertaken.

\section{Necropsy}

The animals were then sacrificed and the thoracic and abdominal vagal systems dissected to confirm that vagotomy had been complete. The balloon was removed from the stomach and the isolated balloon pressure responses to filling and emptying were checked and compared with the readings obtained from the isolated balloon before commencing the experiment.

SERIES B

In the remaining 10 animals (series $B$ ) the experimental programme was modified as follows:

\section{Basal state}

The responses of the intact innervated stomach to filling and emptying were measured in exactly the same way as in series $A$.
Basal state after isolation of the vagi

The anterior and posterior vagal fibres were then carefully isolated by dissection at the oesophageal hiatus and each set of fibres loosely encircled by an untied ligature. The basal readings were then repeated.

\section{Incomplete vagotomy}

The ligature encircling the anterior vagal fibres was then tied and the enclosed nerve divided. A further series of pressure measurements in response to filling and emptying was recorded. In four of the 10 animals the posterior vagus rather than the anterior was divided at this stage in the experiment.

Thereafter the series B experiments proceeded as in series $\mathrm{A}$ with division of the remaining vagal fibres at the appropriate stage.

\section{VARIATIONS IN ANAESTHETIC TECHNIQUE}

Of the 10 animals in each series, eight were anaesthetized by intravenous nembutal alone while two were anaesthetized by induction with thiopentone followed by the oxygen, nitrous oxide, and halothane mixture described above.

\section{BALLOON CHARACTERISTICS}

Filling of an isolated balloon with $100 \mathrm{ml}$ increments of saline produced a plateau response after an initial steep pressure rise as exemplified by Figure 2 .

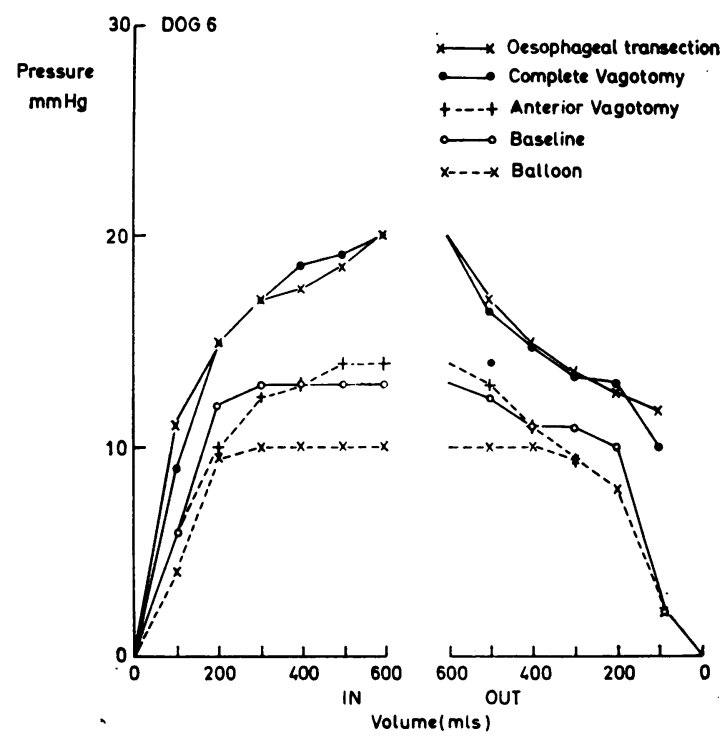

Fig. 2 A set of typical pressure responses to gastric filling and emptying $(\operatorname{dog} 6$, series $A)$. 
The pressure responses of the balloon remained constant throughout the experiment, the maximum recorded variation in the end-filling pressure of an isolated balloon between the beginning and end of each experiment being $1 \mathrm{~mm} \mathrm{Hg}$. Despite this reproducibility of individual pressure-volume characteristics, $600 \mathrm{ml}$ of saline produced a relatively wide range of end-filling pressures in different ballons (mean end-filling pressure of 20 balloons; $10.8 \pm 1.26 \mathrm{~mm} \mathrm{Hg}$, range 8 to $13.5 \mathrm{~mm} \mathrm{Hg}$ ).

In all subsequent results, the balloon component of measured intragastric pressure has been subtracted in the expression of end-filling pressure values.

\section{BASAL STATE}

In all 20 animals, filling the intact innervated stomach with $600 \mathrm{ml}$ of saline resulted in modest end-filling pressures. The mean end-filling pressure for all 20 experiments was $2.40 \pm 2.11 \mathrm{~mm} \mathrm{Hg}$ (Fig. 3). The reproducibility of the end-filling pressure was assessed in four animals subjected to four sequences of filling and emptying of the stomach in the basal state: all values were within $10 \%$ of the first endfilling pressure reading.

\section{COMPLETE VAGOTOMY}

Gastric adaptation was impaired by complete vagotomy in all 20 animals resulting in an increase in mean end-filling pressure to $9.62 \pm 3.29 \mathrm{~mm} \mathrm{Hg}$ (range 3 to $17.5 \mathrm{~mm} \mathrm{Hg}$ ) as shown in Figure 3. The difference in mean end-filling pressure between the basal state and after complete vagotomy in the 20 animals is statistically significant ( $t$ test for paired values, $t=11.06, P<0.001$ ). There was a rise in endfilling pressure after complete vagotomy in all animals when compared to end-filling pressure in the basal state. In 19 of the 20 animals this rise in endfilling pressure was greater than an arbitrary $50 \%$ of the basal end-filling pressure values (Tables I and II).

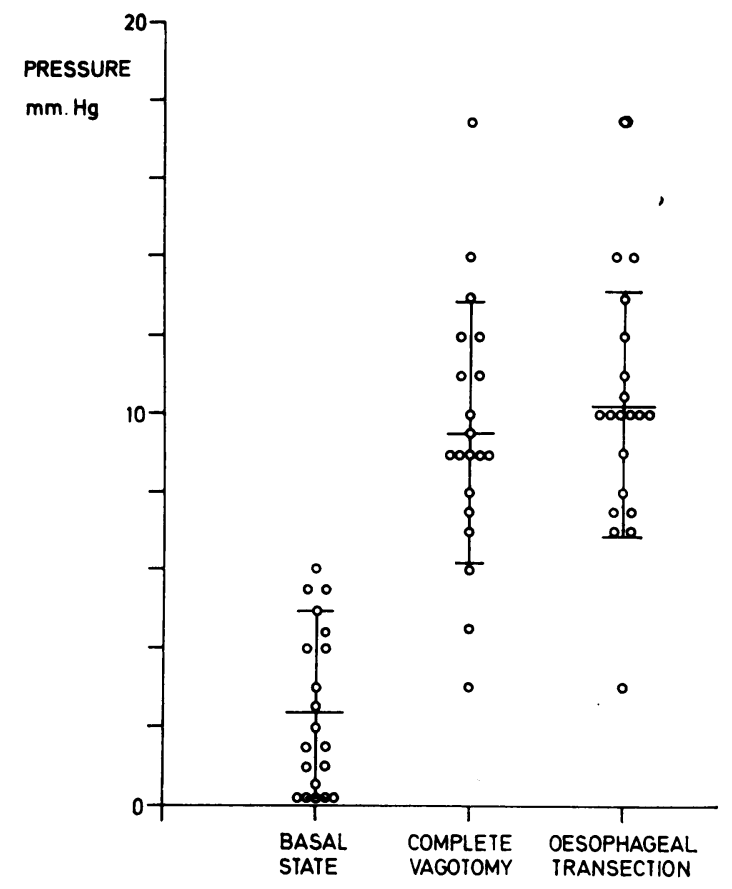

Fig. 3. The effect of complete vagotomy and oesophageal transection on end-filling pressures in all 20 animals (series $A$ and series $B$ ). The mean and standard deviation are shown for each set of results.

\section{OESOPHAGEAL TRANSECTION AND}

NECROPSY

Transection of the oesophagus produced little further rise in end-filling pressures, the mean value after transection being $10.05 \pm 3.14 \mathrm{~mm} \mathrm{Hg}$ (Fig. 3). Of the 20 animals, 10 showed an increase in endfilling pressure, three showed a decrease, and seven showed no change. Necropsy confirmed that a complete vagotomy had been achieved in all animals by the end of the experiment.

\begin{tabular}{|c|c|c|c|c|}
\hline Experiment No. & Basal State & Incomplete Vagotomy & Complete Vagotomy & Oesophageal Transection \\
\hline $\begin{array}{r}1 \\
2 \\
3 \\
4 \\
5 \\
6 \\
7 \\
8 \\
9 \\
10\end{array}$ & $\begin{array}{l}0.5 \\
4.5 \\
0.5 \\
5.5 \\
2.5 \\
3.0 \\
0.0 \\
1.0 \\
0.0 \\
4.0\end{array}$ & $\begin{array}{l}4 \cdot 5 \\
4 \cdot 0 \\
6 \cdot 0^{1} \\
5 \cdot 0^{1} \\
4 \cdot 5^{1} \\
4 \cdot 0 \\
7 \cdot 0 \\
4 \cdot 5 \\
5 \cdot 0 \\
6 \cdot 0^{1}\end{array}$ & $\begin{array}{l}9.0 \\
12.0 \\
9.0 \\
17.5 \\
5.0 \rightarrow 7.0 \\
10.0 \\
9.0 \\
4.0 \rightarrow 9.0 \\
7.0 \\
11.0\end{array}$ & $\begin{array}{r}10.0 \\
10.5 \\
9.0 \\
17.5 \\
7.0 \\
10.0 \\
12.0 \\
10.0 \\
7.5 \\
10.0\end{array}$ \\
\hline Mean ( \pm SD) & $2 \cdot 15 \pm 2.08$ & $5.05 \pm 0.98$ & $10.05 \pm 3.04$ & $10.35 \pm 2.90$ \\
\hline
\end{tabular}

Table I End-filling pressures in series $A$

${ }^{1}$ Animals in which the posterior vagi were divided before the anterior vagi. 


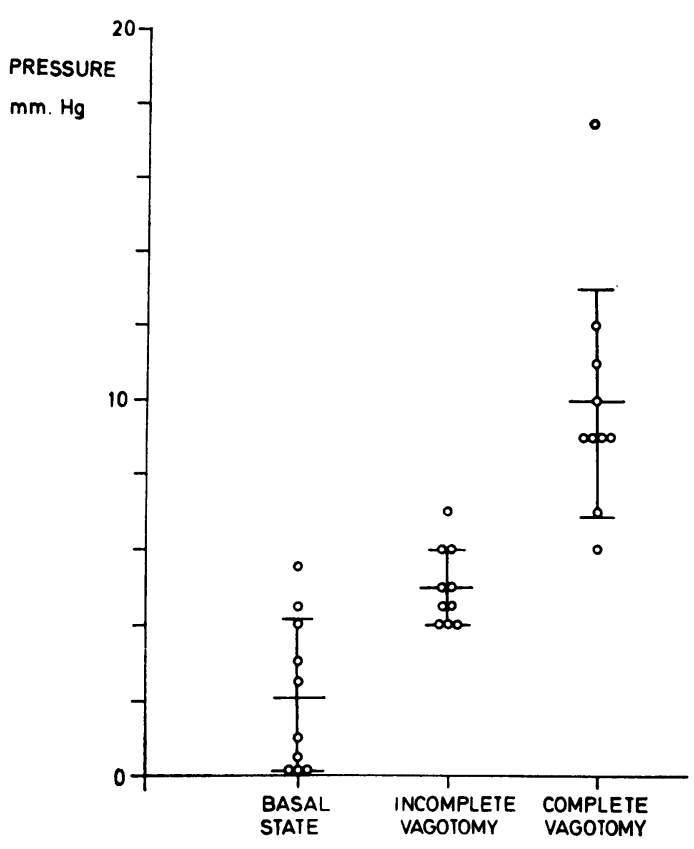

Fig. 4 Series A: the effect of incomplete and complete vagotomy on end-filling pressure. The mean and standard deviation are shown for each set of results.

The results of the two series will now be considered separately with regard to the differences observed after isolation of the vagi and incomplete and complete vagotomy.

SERIES A

There was a small but appreciable tendency for the end-filling pressure to increase after incomplete vagotomy (mean value for 10 animals $5.05 \pm 0.98$ $\mathrm{mm} \mathrm{Hg}$, range 4.0 to $7.0 \mathrm{~mm} \mathrm{Hg}$ ) when compared to the basal state (mean basal end-filling pressure $2 \cdot 15$ $\pm 2.08 \mathrm{~mm} \mathrm{Hg}$, range 0 to $5.5 \mathrm{~mm} \mathrm{Hg}$ ) (Fig. 4). On completion of the vagotomy the mean end-filling pressure rose further to $10.05 \pm 3.04 \mathrm{~mm} \mathrm{Hg}$ (range 7.0 to $17.5 \mathrm{~mm} \mathrm{Hg}$ ), a rise which is statistically significant ( $t$ test for paired values, $t=4.87$, $P<0.001$ ). In individual experiments this pressure rise exceeded an arbitrary $25 \%$ of the end-filling pressure after incomplete vagotomy in all animals and in seven cases the rise exceeded $50 \%$. In two animals (experiments nos. 5 and 8) a further search at the hiatus revealed additional intact vagal fibres and a further increase in end-filling pressure of $2 \mathrm{~mm} \mathrm{Hg}$ and $5 \mathrm{~mm} \mathrm{Hg}$ respectively was produced by division of these fibres. Animals in which the posterior vagi were divided before the anterior showed no marked difference in response to the other animals in the series (Table I).

SERIES B

Isolation of the vagi without division raised the mean end-filling pressure from the basal value of $2.65 \pm 2.27 \mathrm{~mm} \mathrm{Hg}$ (range 0 to $6.0 \mathrm{~mm} \mathrm{Hg}$ ) to $6.55 \pm 3.24 \mathrm{~mm} \mathrm{Hg}$ (range 2 to $12.0 \mathrm{~mm} \mathrm{Hg}$ ), a rise which is statistically significant $(t$ test for paired values, $t=3 \cdot 16, P>0.02$ ) and which is displayed in Figure 5. Isolation of the vagi produced an increase in end-filling pressure in all animals which, in all but two instances, exceeded an arbitrary $50 \%$ of the basal end-filling pressure value. The division of one set of vagal fibres produced a small additional rise in mean end-filling pressure $(7.80 \pm 3.20 \mathrm{~mm} \mathrm{Hg}$, range 4.5 to $12.5 \mathrm{~mm} \mathrm{Hg}$ ) while completion of the vagotomy raised the mean end-filling pressure further to $9.20 \pm 3.63 \mathrm{~mm} \mathrm{Hg}$ (range 3 to $14 \mathrm{~mm} \mathrm{Hg}$ ). This difference between the mean end-filling pressures after incomplete vagotomy and after complete vagotomy is not statistically significant ( $t$ test for paired values, $t=1.95, P>0.05$ ). In experiment no. 12 a further search at the oesophageal hiatus revealed residual vagal fibres after vagotomy had been presumed complete. The division of these fibres produced a further increase in end-filling pressure of $1.5 \mathrm{~mm} \mathrm{Hg}$. The four animals in which the posterior vagi were divided before the anterior showed no marked difference in response to the other six series B animals (Table II).

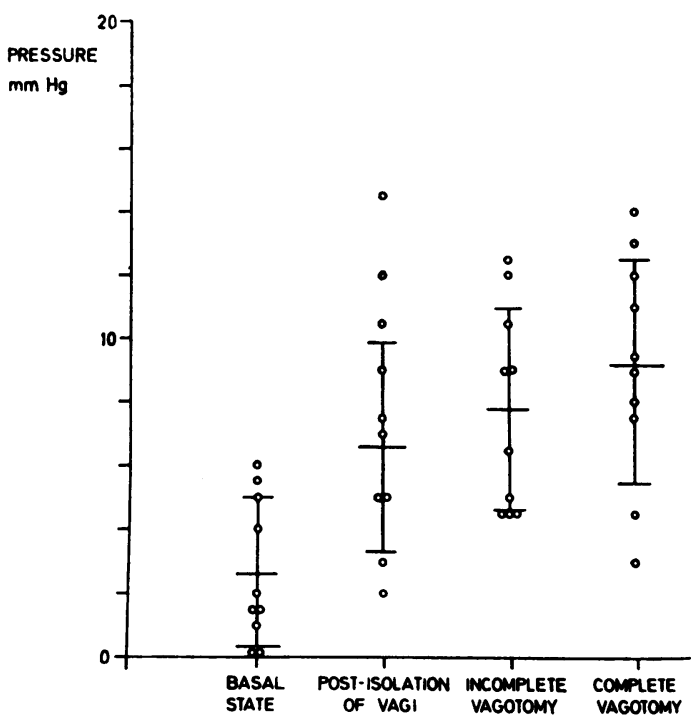

Fig. 5 Series B: the effect of preliminary isolation of the vagi on end-filling pressures. The mean and standard deviation are shown for each set of results. 


\begin{tabular}{|c|c|c|c|c|c|}
\hline Experiment No. & Basal State & $\begin{array}{l}\text { After Isolation of } \\
\text { Vagi }\end{array}$ & $\begin{array}{l}\text { Incomplete } \\
\text { Vagotomy }\end{array}$ & $\begin{array}{l}\text { Complete } \\
\text { Vagotomy }\end{array}$ & $\begin{array}{l}\text { Oesophageal } \\
\text { Transection }\end{array}$ \\
\hline $\begin{array}{l}11 \\
12 \\
13 \\
14 \\
15 \\
16 \\
17 \\
18 \\
19 \\
20\end{array}$ & $\begin{array}{l}2.0 \\
1.0 \\
0.0 \\
1 \cdot 5 \\
6.0 \\
5 \cdot 5 \\
5 \cdot 0 \\
4 \cdot 0 \\
0.0 \\
1 \cdot 5\end{array}$ & $\begin{array}{r}12 \cdot 0 \\
7 \cdot 5 \\
2 \cdot 0 \\
3 \cdot 0 \\
7 \cdot 0 \\
10 \cdot 5 \\
9 \cdot 0 \\
5 \cdot 0 \\
5 \cdot 0 \\
4 \cdot 5\end{array}$ & $\begin{array}{c}9 \cdot 0 \\
4 \cdot 5^{1} \\
4 \cdot 5 \\
4 \cdot 5 \\
6 \cdot 5 \\
12 \cdot 0^{1} \\
10 \cdot 5^{1} \\
5 \cdot 0^{1} \\
9 \cdot 0 \\
12 \cdot 5\end{array}$ & $\begin{array}{l}12.0 \\
6 \cdot 0 \rightarrow 7 \cdot 5 \\
4 \cdot 5 \\
3 \cdot 0 \\
8 \cdot 0 \\
13 \cdot 0 \\
9.0 \\
11.0 \\
9.5 \\
14.5\end{array}$ & $\begin{array}{r}13 \cdot 0 \\
7 \cdot 5 \\
7 \cdot 0 \\
3 \cdot 0 \\
10.0 \\
14 \cdot 0 \\
8 \cdot 0 \\
11 \cdot 0 \\
10.0 \\
14 \cdot 0\end{array}$ \\
\hline Mean ( \pm SD) & $2 \cdot 65 \pm 2 \cdot 27$ & $6.55 \pm 3.24$ & $7 \cdot 80 \pm 3 \cdot 20$ & $9.20 \pm 3.63$ & $9.75 \pm 3.49$ \\
\hline
\end{tabular}

Table II End-filling pressures in series $B$

${ }^{1}$ Animals in which the posterior vagi were divided before the anterior vagi.

VARIATIONS IN ANAESTHETIC TECHNIQUE

The mean end-filling pressure in the basal state was $2 \cdot 84 \pm 2 \cdot 12 \mathrm{~mm} \mathrm{Hg}$ (range 0 to $6 \mathrm{~mm} \mathrm{Hg}$ ) in the 16 animals anaesthetized solely by intravenous nembutal compared to $0.625 \pm 0.75 \mathrm{~mm} \mathrm{Hg}$ (range 0 to 1.5 $\mathrm{mm} \mathbf{H g}$ ) in the four animals anaesthetized in the alternative manner described. This difference is not quite statistically significant $(\mathrm{t}=2.03, \mathrm{p}>0.50)$, but a larger series would be necessary before this could be stated with certainty.

\section{Discussion}

There is now no doubt that gastric adaptation is impaired by complete vagotomy. Staadas and Aune (1970) evaluated patients two to three weeks after vagotomy and found adaptation to be still impaired at this time. Indeed Aune (1969) has suggested that the altered pressure responses may be longstanding and could contribute to the derangements in gastrointestinal motility which may occur after vagotomy. The work of Koster and Madsen (1970) was concerned with aiterations in adaptation at the time of vagotomy and is therefore of greater relevance in the present context. While confirming that adaptation was impaired immediately after vagal section, these authors were unable to correlate the observed increases in intragastric filling pressures at operation with the results of postoperative insulin tests. Thirteen duodenal ulcer patients shown subsequently to be Hollander negative by insulin tests had a mean maximum increase in intragastric pressure of $6 \mathrm{~mm}$ $\mathrm{Hg}$ at operation as opposed to $5 \mathrm{~mm} \mathrm{Hg}$ in a group of five patients later found to have positive insulin tests. While the authors comment on the problems surrounding the validity of the insulin tests and its ultimate value in defining recurrent ulcer patients, their results raise serious doubts regarding the application of gastric adaptation as an intraoperative assessment of complete vagotomy.
In our own animal experiments, the immediate impairment of adaptation by complete vagotomy is confirmed. The results of series $\mathbf{A}$ indicate that the impairment may not be of the all-or-none variety as the mean end-filling pressure after incomplete vagotomy is greater than the mean basal end-filling pressure by $2.90 \mathrm{~mm} \mathrm{Hg}$. However, the magnitude of the increase is much greater after complete vagotomy and in all animals the end-filling pressure after complete vagotomy is at least $25 \%$ in excess of the pressure recorded after incomplete vagotomy. While this seems encouraging at first sight, it must be remembered that these differences are relative and that an absolute end-filling pressure which denotes a complete vagotomy in one animal may represent an incomplete vagotomy in another (Fig. 4). In the human operative situation, problems in interpretation would undoubtedly arise because of these considerations. If postvagotomy end-filling pressure could be predicted beforehand then this difficulty would be overcome. 'Medical vagotomy' has proved an unsuccessful method of prediction in another context, and in preliminary experiments of our own we have not been able to predict the postvagotomy end-filling pressure.

The results of our series B experiments raise further problems which may have more widespread implications. While adaptation is again significantly impaired by complete vagotomy, the major rise in end-filling pressure occurs immediately after isolation of the vagi before their division (Fig. 5). The subsequent division of one set of vagal fibres produced little further alteration in mean end-filling pressure and even after complete vagotomy the mean end-filling pressure is only $2.65 \mathrm{~mm} \mathrm{Hg}$ in excess of the mean pressure observed after mere isolation of the nerves. It appears that the trauma of vagal isolation may seriously impair adaptation and it is therefore conceivable that the intragastric pressure responses to filling could be compatible 
with complete vagotomy while substantial nerve trunks remained undivided. Trauma to the stomach rather than the vagi is unlikely to account for these findings, as handling of the stomach was restricted to a minimum, and, further, the results of series $\mathbf{A}$ would not substantiate this explanation.

While general anaesthesia undoubtedly depresses vagal activity, particularly when a long-acting barbiturate such as nembutal is employed, it was considered essential to the aims of the present experiments to employ a general anaesthetic if an intraoperative test was to be assessed. While no firm conclusions can be drawn from a comparison of the two anaesthetic methods employed here, there is a suggestion that the animals anaesthetized by nembutal showed higher mean end-filling pressures in the basal state than their counterparts anaesthetized by the alternative method. This tendency has been maintained in a further small series of unpublished experiments and may reflect a relative impairment of reflex vagal function by nembutal. However, the depressive effect of any form of anaesthesia is unlikely to influence the overall pattern of our results, based as they are on relative pressure changes, each animal acting as its own control. Thus, adaptation changes do not seem to offer a useful aid in the confirmation of complete vagotomy at the time of operation. First, it would be difficult to decide whether one observed end-filling pressure value did in fact reflect a state of complete vagotomy and secondly we have demonstrated major increases in end-filling pressure after merely isolating the nerves. Furthermore, the method is time consuming and would necessitate the introduction of a balloon either by a duodenotomy or the nasogastric route. In dismissing adaptation in this way, the possibility that operative trauma may interfere with the interpretation of other intraoperative tests must be considered. It is possible that the electrical test of Burge may remain valid in that residual vagal strands could continue to conduct an electrical impulse after artificial stimulation while their ability to conduct physiological signals is impaired. The confirmation of this thesis would seem important. Whether similar considerations would apply to Grassi's method is again open to speculation. It is now realized that the results of postoperative insulin tests may alter as the length of time after the operation increases. As Gillespie, Elder, Gillespie, Kay, and Campbell (1970) have shown, there is a tendency for some tests that were originally negative to become positive and for tests originally showing a late positive response to become positive in the first hour after insulin. Many mechanisms, including nerve regeneration, sprouting, and recovery from neuropraxia, have been suggested as the basis for these findings. Our results suggest that a state of neuropraxia may readily be produced by operative trauma and could mask the existence of intact vagal fibres for some months after surgery.

The authors would like to thank Mr D. G. Wailling for his help with the statistical analyses.

Requests for reprints should be addressed to I. B. McLeod, Department of Clinical Surgery, University of Edinburgh.

References

Aune, S. (1969). Intragastric pressure after vagotomy in man. Scand. J. Gastroent., 4, 447-452.

Burge, H., and Vane, J. R. (1958). Method of testing for complete nerve section during vagotomy. Brit. med. J., 1, 615-618.

Cannon,W. B., and Lieb, C. W. (1911). The receptive relaxation of the stomach. Proc. Amer. physiol. Soc., 27, xiii.

Cooke, W. M., Talbot, I. C., Welbourn, R. B., and Cox, A. G. (1970). Leucomethylene-blue as aid to complete vagotomy. Lancet, 1 , 864-865.

Gillespie, G., Elder, J. B., Gillespie, I. E., Kay, A. W., and Campbell, E. H. G. (1970). The long-term stability of the insulin test. Gastroenterology, 58, 625-632.

Grassi, G. (1971). A new test for complete nerve section during vagotomy. Brit. J. Surg., 58, 187-189.

Koster, N., and Madsen, P. (1970). The intragastric pressure before and immediately after truncal vagotomy. Scand. J. Gastroent., $5,381-383$.

Lee, M. (1969). A selective stain to detect the vagus nerve in the operation of vagotomy. Brit. J. Surg., 56, 10-13.

Stadaas, J., and Aune, S. (1970). Intrasastric pressure/volume relationship before and after vagotomy. Acta. chir. scand., 136, 611615. 